\title{
La ocupación de Melilla en 1497 y las relaciones entre los Reyes Católicos y el Duque de Medina Sidonia
}

Antonio Bravo Nieto

El 17 de septiembre de 1497 se ocupa la abandonada villa de Melilla en la Costa Norteafricana. Este acto en sí puede ser el inicio de un largo y apasionante tema, pero vamos a intentar concebirlo en este estudio como punto final.

Como consecuencia, pues este hecho militar y político está condicionado precisamente por toda una serie de circunstancias que no solo afectaban a la política interior española sino a sus relaciones internacionales.

\section{A. Algunas visiones de España sobre 1497}

No intentamos desde luego abarcar un panorama amplio en este capítulo, sino más bien abordar algunos de los hechos de los que pensamos pueden derivarse consecuencias para la ocupación de Melilla y la llamada "Causa Africana".

Los dividiremos en dos amplios apartados, en el primero englobamos las luchas que se sucedieron entre monarquía y nobleza con todas sus connotaciones y en el segundo las que se denominan grandes empresas de los Reyes Católicos: Guerra de Granada, América y Guerras con Francia e Italia. Finalmente nos preguntaremos si hubo realmente una política africana en los Reyes Catolicos.

\section{A.1. Monarquía-Nobleza y su concepción del Estado}

Gran parte de la bibliografía referente a la ocupación de Melilla (ver Anexo) se ha ocupado en dilucidar si en esta accción tuvo un mayor peso el Duque de Medina Sidonia o los Reyes Católicos. Esta dualidad queda reflejada en la pugna que la monarquía establece contra la alta nobleza para acaparar el control del poder político que ésta había ido adquiriendo en épocas de debilidad real (Enrique IV).

Este "desequilibrio" político no fue positivo para casi nadie, si exceptuamos a la misma alta nobleza que iba enriqueciéndose paulatinamente con diferentes rentas, pues poseía recursos cuantiosos, defendidos por un complicado sistema de privilegios.

Pero ¿cuál era su ideal o concepción de Estado? 
José Cepeda ${ }^{1}$ indica que éste se reduciría a la defensa y engrandecimiento de sus propias haciendas. Su acción siempre individual no encontró más campo que las luchas intestinas en donde entraban en juego cuestiones de honor junto a motivos económicos.

En este sentido la alta nobleza actuó en la línea sefialada por Julio Valdeón ${ }^{2}$, arrancando de la monarquía rentas e invadiendo otros ámbitos para enriquecer sus haciendas y prestigio.

Las luchas fraticidas, según Cepeda, iban aniquilando su fuerza y prestigio: la inseguridad se adueñó de todos los ambientes.

Este estado de cosas no era querido por nadie, y existía un ánimo general partidario del orden, y que en última instancia venfa garantizado por la monarquía y por las Hermandades.

Los Reyes Católicos inician una línea de reforzamiento del poder monárquico. Esta institución comienza a fortalecerse e impone su justicia a todos los niveles. Siguiendo a Cepeda, vemos como la nobleza cuando comienza a ver agotados sus recursos en las continuas luchas en las que había intervenido, comienza a desear una mayor estabilidad.

En el fondo lo que subyace es el interés económico por legitimar su situación, más que ventajosa, y los Reyes Católicos utilizan esto para dominarles.

La pugna Monarquía-Nobleza, no se establece a niveles económicos o sociales. Los Reyes desean acaparar la acción y decisión políticas, pero nunca pondrán en tela de juicio la situación social o económica del estamento nobiliario.

En esta época, como bien ha señalado Ladero Quesada ${ }^{3}$ se produce una estabilización del poder señorial pues aún corrigiendo los abusos cometidos, no se atacaba el estatus de esta clase.

La nobleza por tanto no salió debilitada de esta lucha, pero su puesto político, la preeminencia en la toma de decisiones o su influencia sobre la marcha de los asuntos generales del Estado, quedará a partir del reinado de los Reyes Católicos muy mermada.

Frente al carácter individualista de los nobles, con su cortedad de miras, la realeza opondrá una visión más general y con una amplitud de planteamientos que le permitirá la acometida de grandes empresas.

Lo de Melilla creemos por tanto, no va a ser una excepción.

(1) CEPEDA ADAN, José, En torno al concepto de Estado en los Reyes Católicos, Madrid, CSIC, 1956, p. 145-197.

(2) VALDEÓN BARUQUE, Julio, Los conflictos en el reino de Castilla en los siglos XN y XV, Madrid, Siglo XXI, 1975.

(3) LADEROQUESADA, Miguel Angel, "Los señoríos medievales en el ámbito de Cádiz y Jerez de la Frontera", En la España Medieval, Estudios en la memoria del Profesor Salvador de Moxb, Universidad Complutense, Madrid, año 1982, Volumen I, P. 543-572. 


\section{A.2. Las empresas de los Reyes Catolicos}

\section{- La conquista de Granada}

Recién terminada por los Reyes Católicos la Gucrra Civil que siguió a su subida al Trono, emprendieron una nueva empresa: la conquista del último reino musulmán que quedaba en la península Ibérica, Granada, que finalizaría en 1492.

El carácter de la conquista agrupa factores de tipo religioso, económico y militar, y con ella los Reyes Católicos se propusieron finalizar esta molesta presencia a la vez que materializaban su idea de unificación peninsular.

Queremos tomar esta referencia porque se ha querido ver un carácter de reconquista en la ocupación de Melilla, una continuación de lo de Granada.

Hagámosnos ahora varias preguntas: ia qué idearios respondía la conquista de Granada? ¿qué suponía para Castilla y Aragón e incluso para los Reyes Católicos esta conquista? ituvo participación la alta nobleza en ella? $\mathrm{Y}$ en caso positivo ifue principal o secundaria?

La respuesta a estas interrogaciones podrían matizarnos el carácter de Reconquista y tal vez las diferencias que pudieran verse en relación con lo de Melilla, como veremos más adelante.

\section{-América}

El Descubrimiento de América (1492) fue otro hecho fundamental de esta época pues iba a variar en gran medida la historia de España.

Se ha venido diciendo que América concentró las energías hispanas (junto con Europa) e impidió la posibilidad de una expansión por Africa. Incluso la historiograffa tradicional sobre Melilla, daba por sentada la oposición de Cristóbal Colón a la ocupación de esta villa ${ }^{4}$.

Tenemos que decirsiguiendo a Patricio Prieto, que América comenzó a concentrar realmente esfuerzos notables a partir de 1519 por lo que pensamos no debe imputarse al tema americano una dispersión de esfuerzos que imposibilitasen en su momento una expansión en Melilla o en el Norte de Africa en estos momentos iniciales (fines del siglo XV principios del XVI).

(4) ZURITA, Jeronimo, Anales. Historia del Rey Don Hernando el Católico..

Tomo V, Zaragoza, Herederos de Pedro Lanaje, 1580, Libro III, capírulo XVI, folio 106.

Aunque esta apreciación ha venido siendo esgrimida hasta la actualidad, Prieto Lloveras, Patricio en su artículo "La conquista de Mclilla y el tercer viaje de Colón", Africa Revista de Tropas Coloniales", $n^{2} 118,1951$, p. 484-488, ha demostrado que no pudo haber interferencias entre el tercer viaje de Colón y la ocupación de Melilla, por los diferentes tipos de naves empleadas y la estructura organizativa de ambas empresas. 
El esfuerzo europeo español, al menos en los últimos años del siglo $\mathrm{XV}$, va a centrarse en las continuas guerras con Francia que se desplazarán hasta tierras italianas.

Precisamente en Italia y siguiendo pautas de la política exterior de Aragón va a producirse una intervención de gran envergadura que arrojaría una poderosa influencia espaniola en parte de esta Península.

No perdamos de vista la cronología de estas guerras ${ }^{5}$ que ocupan desde 1494 hasta 1504, pues su periodización nos va a mostrar realmente cuales eran los intereses principales de los Reyes Católicos y qué papel pudiera cumplir la ocupación de Mclilla en 1497.

Llegado el momento nos queda preguntarnos sobre la existencia o inexistencia de una política africana.

Casi toda la historiografía que se ha ocupado del tema lo hace de modo un tanto marginal ${ }^{6}$. Se ha partido, desde nuestro punto de vista, de algunas acciones aisladas (la ocupación de Melilla entre ellas) al menos hasta 1505, para intentar justificar su existencia.

Otros historiadores, como García Figueras ${ }^{7}$ han cstudiado la paralización de esta política africana a causa de otros asuntos (otras polf́ticas diriamos nosotros) mús apremiantes o importantes.

Pero, si esta línea estuvo casi sicmpre paralizada por un motivo u otro, ¿no es lo mismo que hablar de la inexistencia a niveles prácticos de un proyecto coherente de actuación en el Norte de Africa? La realidad da la razón a esta hipótesis ¿por qué tanto interés en justificar esa política africana de los Reyes Católicos cuando en la práctica fueron unas acciones muy limitadas y muy concretas llevadas a cabo la mayor parte de las veces por una actitud defensiva cuando otros intervenían (dígase turcos y piratas)?, ¿acaso ha habido un interés especial en justificar la presencia española en el siglo XX en la zona del Protectorado de Marruccos, a través de un africanismo que hundirfa sus raíces en el Testamento de Isabel la Católica?

Demasiadas preguntas para ser contestadas sin una investigación seria y metodológica.

Diremos sin embargo que hasta 1505, la acción española en Africa fue marginal (Melilla 1497) y extremadamente limitada tanto en medios humanos como materiales: se ocupaba un punto costero fácilmente defendible para asentarse en él con fines defensivos y controlar el entorno.

\footnotetext{
(5) GARCIA FIGUERAS, Tomás, "La ocupación de Melilla en el pensamiento de los Reyes Católicos", Conmemoración del 450 Aniversario de la Conquista de Melilla. Curso de Conferencias, Melilla 15 y 17 septiembre 1947, p.: 13-36.

(6) Varios, Curso de Conferencias sobre la Política Africana de los Reyes Católicos, Valladolid, Instituto de Estudios Africanos, 1951, 6 Volúmenes.

(7) GARCIA FIGUERAS, Tomás, art. cit. p.: 13-36.
} 
¿Dónde estaba el idcario de ocupación de todo el Norte de Africa o la idea de Cruzada teniendo en cuenta que nunca se intentó cristianizarla zona? Volveremos más tarde sobre este tema.

\section{B. La nobleza andaluza a fines del siglo XVI: el Duque de Medina Sidonia}

Vamos a intentar analizar cual era cl estado de la nobleza en Andalucía a fines del siglo XV y concretamente el linaje de los Guzmanes, representado por el ducado de Medina Sidonia,

\section{B.1. La población en Andalucía}

Según los censos fiscales de 1528-1536 había en Castilla unos 4.500 .000 habitantes $^{8}$ que suponían el $78,39 \%$ del total en los diferentes reinos hispanos.

Inmerso en ella, cl reino de Sevilla tenía mientras tanto unos 400.000 habitantes. Se calcula que un $13 \%$ de los pecheros vivían en Andalucía, que era una región con demografía pujante y una vitalidad de la que carecían otras regiones o reinos.

Este hecho le va a permitir participar activamente en diversas empresas con el soporte básico de su demografía.

\section{B.2. El régimen de señorío}

También es interesante abordar la institución del señorio en tierras andaluzas, puesto que sobre ella se basaba gran parte del poder de estos nobles?.

Las ticrras de señorío ocupaban la mayor parte de las actuales provincias de Cádiz y Huelva. Sólo dependían directamente de los Reyes Católicos (realengo) las villas de Jerez, Puerto Real, Cádiz y Gibraltar.

Scñorío y realengo eran dos modos de gobierno y administración del territorio y los hombres que lo habitaban. En el señorío el monarca sólo conserva un dominio eminente pero subroga el ejercicio del gobicmo y la Administración en manos de un aristócrata.

Para la nobleza andaluza rigen las mismas características que hemos apuntado

(8) Sobre la población en Andalucía véase:

-RUIZ MARTIN, Felipe, "La población española a comienzo de los tiempos modernos", Cuadernos de Historia, $\mathrm{n}^{2} 1$, 1967, p.: 189-202.

- LADERO QUESADA, Miguel Angel, "La población de Andalucía en el Siglo XV. Notas provisionales", Revista Anuario de Historia Económica y Social, n² 2, 1969, p.: 479-495.

-DOMINGUEZ ORTIZ, Antonio, "La población del Reino de Sevilla en 1534", Cuadernos de IIistoria, $\mathrm{n}^{2} 7,1977$, p.: 337-356.

(9) LADERO QUESADA, Miguel Angel, "Los Scñoríos Medievales en el ámbito de Cádiz y Jerez de la Frontera", En la España Medieval Estudios en la memoria del profesor Salvador de Moxó, Universidad Complutense, Madrid, 1982, vol. I, p.: 543-572. 
para el resto de esta clase, pero aquí tal vez más acusadas por la personalidad y el poder de uno de sus máximos representantes: el Duque de Medina Sidonia.

No nos vamos a remontar a la formación del linaje y a su progresivo enriquecimiento ${ }^{10}$, digamos que su poder económico, político, social y militar era enorme.

\section{B.3. Su poder económico estaba basado en el señorío que ejercía sobre extensas zonas de Andalucia, lo que se traducía en cuantiosas rentas que ha estudiado Enma Solano".}

Las rentas de los Medina Sidonia eran muy amplias: jurisdiccionales, las tomadas a la Corona o a la Iglesia, mercedes reales sobre rentas o cargos públicos y territoriales.

Su distribución también estaba equilibrada por sectores: primario (agricultura, forestal, pesca), secundario (artesanado) y terciario (comercio), y le proporcionaban un total de 10.938.901 maravedises en 1509 .

Socialmente podía considerarse la cúspide de la pirámide en todos sus señoríos. Ladero $^{12}$ ha calculado que un $66 \%$ de los 65.000 habitantes que vivían en la actual provincia de Cádiz, eran de sefiorío. Los estados de Medina Sidonia disponían de 3.956 vecinos, o sea unos 20.000 habitantes.

De todo esto se desprende un poder político evidente. Ya veíamos que en épocas de inestabilidad los nobles arrancaron privilegios y rentas a la monarquía. También que éstos habían fomentado la inseguridad en amplias zonas de la Península.

La llegada de los Reyes Católicos marcará una nueva etapa, incluso para el poderoso Medina Sidonia. La monarquía no va a atacar su estatus social pero si intentará corregir abusos anteriores.

\section{B.4. Las relaciones del Duque de Medina Sidonia con los Reyes Católicos}

Para recortar las amplias prerrogativas de la nobleza comienza a funcionar de nuevo la Hermandad en Andalucía desde 1476, con gran pesar del Medina Sidonia, pues se controlaban asf las continuas guerras entre bandos nobiliarios: Arcos-Medina Sidonia.

Pero la instauración de la seguridad no bastaba, aunque fuera importante. La realeza pretendía situar a la nobleza en el papel que pensaba debía desempeñar en su concepción del estado.

"La nobleza no ha llegado a plantearse un dominio del estado en función de una

(10) Ibi dem.

(11) SOLANO RUIZ, Enma, "La Hacienda de las Casas de Medina Sidonia y Arcos en la Andalucía del siglo XV", Archivo Hispalense, número 188, 1972, p.: 85-176.

(12) LADERO QUESADA, Miguel Angel, "Los señoríos medievales en el ámbito de Cádiz y Jerez de la Frontera", art. cit. 
concepción estamental, sino que se trataba nada más de engrandecer en un oportunismo sin futuro, la propia casa y aumentar el número de vasallos y territorios"13.

Evidentemente, el ideario de la monarquía iba mucho más allá, por lo que se produce un alejamiento inmediato de la nobleza de las tomas de decisión políticas del Estado.

"Los reyes pretendían sostener solos sobre sus hombros todo el peso del Gobierno, desconfiando de la habilidad de los grandes que pensaban permanecer en sus casas alejados de la corte mientras se les considerase inútiles"14.

La nobleza mantiene su poder, pero solo a costa de aceptar su nuevo papel político.

$Y$ el Duque, precisamente tuvo que quedarse en sus señoríos mientras España entraba en la Edad Moderna: América e Italia, fueron cometidos en los que no participo.

En la conquista de Granada, prestó dineros y algunas huestes, pero tampoco intervino directamente. Estas guerras beneficiaron, como ha estudiado Marie Claude Gerbet $^{15}$, a Hidalgos y Caballeros sobre todo, y no a la alta nobleza.

Ya habían pasado como dice Cepeda, los tiempos en que la nobleza pudiera obrar por su cuenta ${ }^{16}$.

Recortado su poder político en la toma de decisiones del Estado, también sufrí varias mermas en su patrimonio, sobre todo en el caso de Gibraltar, (que la corona recuperaría finalmente en 1503). Este hecho enturbiaría las relaciones Reyes Católicos-Medina Sidonia, por el firme deseo real de recuperar la plaza ante la negativa perseverante del Duque.

Las nuevas relaciones pasaban evidentemente por la aceptación del Duque del nuevo papel que le tocaba desempeñar en el estado que estaban forjando los Reyes Católicos, muy a su pesar por supuesto.

\section{B.5. El Duque y las relaciones con el Norte de Africa}

El Ducado de Medina Sidonia tuvo siempre una especial relación con el Norte de Africa, por su papel de frontera.

No olvidemos que existran unos contactos comerciales persistentes entre las dos orillas. Pero hagamos una diferenciación geografica que creemos importante.

Las ciudades mediterráneas del Sultanato de Fez habían tenido una especial

(13) CEPEDA ADAN, José, art. cit. p.: 175

(14) PALENCIA, Alonso Femández de, Crónicas de Enrique $N$, tomo II, p.: 352 y sig.

(15) GERBET, Maric Claude, "Les Gucrres et L'Accès a la noblesse en Espagne de 1465 a 1592", Melanges de la Casa de Velazquez VIII, 1972, p.: 295-325.

(16) CEPEDA ADAN, José, art. cit. p.: 169 
preponderancia comercial en sus relaciones con el Al-Andalus y los reinos mediterráneos de Aragón, Mallorca, Génova o Venecia.

Así, eran las villas que más impuestos pagaban a Fez en el siglo XIV, pero la piratería y la paulatina ocupación de la fachada sur de la Península Ibérica por los cristianos fue variando esta situación.

La Costa Atlántica en el siglo XV y XVI concentraba casi todo el Comercio del Sultanato y paralelamente la mediterránea contempló una decadencia irreversible de sus villas: Melilla, Cazaza, Badis y Mezemma ${ }^{17}$.

Digamos pues que estas ciudades pasaron a desempeñar puestos muy marginales en la organización de este sultanato.

Asf, Cádiz, ciudad que tenf́a concesión por parte de los Reyes Católicos del monopolio comercial con Africa ${ }^{18}$, remitfa todos sus intercambios comerciales con el Fez Atlántico.

No perdamos de vista que Cádiz era una de las pocas villas de realengo de la región.

Hay que destacar que casi todo el oro que entraba en España (hasta que cl descubrimiento de América impulsó otras vías) lo hacía por este cauce, y que en 1518 su tráfico suponía un volumen de 200.000 ducados.

Los contactos del Medina Sidonia con la Costa Norteafricana también inclúan razzias contra algunas villas para aprovechar la presa que podía ser muy productiva a veces.

Finalizamos diciendo que hubo contactos que permitieron al Duque conocer más o menos el estado de la costa Norteafricana durante el siglo XV y que pudo posibilitar una imagen tal vez poco realista, como lugar por donde se podía acceder al oro del Sudán o de la que de vez en cuando se extrafan algunas riquezas procedentes de razzias.

Como la organización del Comercio Exterior reposaba sobre el control monárquico, los resultados fiscales escapaban en cierto modo a la nobleza andaluza. ¿Estaría en el pensamiento del Medina Sidonia el tema del tráfico de oro en una posible intervención en la Costa Norteafriana?

\section{La ocupación de Melilla: un aspecto de las relaciones monarquía-nobleza}

\section{C.1. Intentaremos recapitular sobre los móviles que pudieron mover a los Reyes Católicos a una supuesta política sobre Africa (hasta 1505) plasmada en lo de Melilla}

Los móviles económicos eran lejanos, pues ya vimos como la riqueza del Magreb

(17) ZAIM, Fouad, "Le Maroc et l'espace Méditerraneen au moyen Age, IX, XV siecle", Signes du présent, Printemps 1988, n², p.: 77-89.

(18) RUMEU DE ARMAS, Antonio, Cádiz Metrópoli del comercio con Africa en los siglos XV y XVI, Madrid, Ediciones de la Caja de Ahorros de Cádiz, 1976, p.: 7-55 
no estaba precisamente en la fachada mediterránea del Sultanato de Fez.

Tampoco creemos que influyeran móviles religiosos (de especial veneración historiográfica). Si estos fueron una parte importante (pero no exclusivos) en la conquista de Granada, había otros intereses en esta campaña que no influyeron para nada en el tema de Melilla. Difícilmente puede hablarse de una continuación de la Conquista de Granada para argumentar la política africana.

El beneficio de la Bula de Cruzada también ha sido esgrimido y con razón, pero tampoco fue motivo de peso ${ }^{19}$.

Los Reyes Católicos por tanto no se plantearon una reconquista, y tenían claro que las circunstancias eran otras.

Sí pudieron pesar móviles estratégicos. Melilla podía ser un buen avance hacia el corazón del Sultanato de Fez, y en todo caso era una buena posición costera, fácil de defender y de abastecer por mar.

Pero este carácter estratégico necesitaba un planteamiento global, o sea una política premeditada y determinada ¿la hubo alguna vez?

Otro tipo de móviles nos parecen más justificados: control del auge de la incipiente piratería berberisca y punto de control para detener agresiones contra la Península.

En el fondo era un planteamiento defensivo lo que determinó la conversion de la abandonada villa de Melilla en una fortaleza, y no en una cabeza de puente ofensiva para una posterior expansión en $1497^{20}$.

Por otra parte esta fecha está inmersa entre acciones de verdadera envergadura: guerras con Francia y campañas en Italia.

La ocupación resulta por tanto difícil de encajar en una línea homogénea o continuada de actuación y no siguieron (hasta ocho años después) otras conquistas o asentamientos, y aun entonces no fueron determinantes ${ }^{21}$.

No nos extrañe por tanto que no hubiera otros impulsos para expandir la ciudad ni un palmo más allá de sus murallas.

(19) IBARRA RODRIGUEZ, Eduardo, en su artículo “La Conquista de Melilla en 1497", La España Moderna, Madrid, LXI, 1894, p.: 121 a 140, ya criticaba que hubiesen sido los móviles religiosos los que determinaran la acción de Melilla.

(20) Ha habido disparidad en relación con la fecha exacta de la ocupación de Melilla: 1496 o 1497, que era reflejo de una inconcreción en las fuentes.

Henry de Castries, en su obra Les Sources inédites de L'Histoire du Maroc. Archives et Biblioteques d'Espagne, T.I, Paris, Ed. Emest Leroux, 1921, introducción, da argumentos sólidos para optar por 1497, fecha aceptada hoy día por todos.

(21) Este hecho ha marcado un silencio casi total de la historiografía (hasta finales del siglo XIX) sobre esta ocupación. La acción africana para esta historiografía comenzaría con las conquistas de OránMazalquivir por Cisneros, en 1505.

Galindo y Vera, León, en su voluminosa obra Historia, vicisitudes y política tradicional de España respecto de sus posesiones en las costas de Africa, Madrid, Imprenta de Manuel Tello 1884, dedica a Melilla 23 líneas!

Sería Ibarra Rodríguez, Eduardo, art. cit. quien reivindique la antelación cronológica de lo de Melilla. 


\section{C.2. ¿Existió algún interés africano del Medina Sidonia?}

El Duque D. Enrique, podía tener otros intereses en la ocupación de Melilla diferentes a los de los Reyes Católicos.

Su nueva situación frente a las fuerzas ejecutivas y de toma de decisión del estado, su alejamiento de la corte, le habían varado en una situación secundaria.

El tráfico de oro desde el Sahara y las abundantes cabalgadas, eran motivos a favor de su intervención pero no determinantes. Pensamos que debieron pesar mucho más otras valoraciones. ¿No podía ser ésta una fórmula para estar de nuevo en vanguardia ante una gran empresa?

Si Medina Sidonia creía en un futuro prometedor de España en Africa, no es nada aventurado pensar que deseaba asegurarse un primer puesto en la gloriosa campania que estaba a punto de iniciarse. Ni más ni menos que una salida honrosísima de su retiro político.

\section{C.3. La ocupación: ¿un acto de los Reyes Católicos o del Duque?}

La bibliografía (Anexo) está ampliamente dividida en la tesitura de quienes fueron los que realmente iniciaron la acción.

En la base existe un problema historiográfico; mientras los cronistas de la Casa Medina Sidonia afirman la autoría del Duque y la aprobación de los monarcas ${ }^{22}$ los cronistas reales afirman que el viaje fue a instancia de la monarquía y ejecutado por el duque ${ }^{23}$.

Como el problema no podemos resolverlo a través de las fuentes, podemos utilizar las hipótesis que hemos venido apuntando a lo largo de nuestro esquema.

De hecho la ocupación la ejecuta el Duque y concretamente su contador Pedro de Estopinán. La iniciativa suponemos pudiera tenerla el Medina Sidonia, pues ya hemos

(22) BARANTES MALDONADO, Pedro, Ilustraciones de la Casa de Niebla 1544, En memorial histórico español publicado por la Real Academia Española de la Historia, bajo la dirección del Sr. D. Pascual de Gayangos. Tomo X y tomo II, capítulo IV, p.: 404 y siguiente. Madrid, Imprenta Nacional, 1857.

MEDINA, Pedro de, Cronista de los Duques Medina Sidonia, Crónica de los muy excelentes señores duques de Medina Sidonia 1561, En CO.DO.IN. Tomo XXXIX, p.: 317-321.

(23) BERNALDEZ, Andrés, Cronista de los Reyes Católicos, Cura de los Palacios, Crónica de Don Fernando y Doña Isabel. C.L.V.I. Publicada en el tomo III de Crónicas de los Reyes de Castilla Colección Rivadeneyra, tomo LXX, p.: 692.

ZURITA, Jerónimo, Anales. Historia del Rey Don Hernando el Católico, de las Empresasy Ligas de Italia compuesta por Gerónimo Zurita. Cronista del Reyno de Aragon. Tomo V, Con licencias y privilegios. Impreso en Zaragoza por los herederos de Pedro Lanajo y Lamorca, Impresores del Reyno de Aragon y de la Universidad, año 1580, libro III, capítulo XVI, folio 106.

PADILLA, Lorenzo de, Crónica de Don Felipe I, llamado elHermoso. En CO.DO.IN. Tomo VIII, p.: 1-267. 
visto que 1497 cra una fecha atípica, aislada y con poco sentido dentro de la política exterior de los Reyes Católicos. Es posible que en esa fecha no hubiera madurado suficientemente la idea de una política africana.

D. Enrique, aprovechándose de la disponibilidad de barcos (una flota había llegado en marzo de 1497 desde Flandes) pudo ejecutar la ocupación que posiblemente había ido gestando.

¿Pero estaban los Reyes Católicos al margen de esta acción? En absoluto, no creemos que el Duque obviara la opinión de los monarcas y menos cuando ya habían quedado muy claras cuales eran las funciones propias de la nobleza en cuanto a la toma de decisiones.

Una cabalgada, una razzia, a las que estaban acostumbrados no eran desde luego la ocupación, reconstrucción y repoblación de una ciudad en un el norte de Africa.

Los monarcas estaban al tanto desde luego, como se desprende de que uno de sus hombres de confianza Francisco Ramírez de Madrid (que participara en tantos servicios y hechos de armas) estuviera en la preparación del viaje, y a él se debe cl sistema para reedificar la ciudad de "cava e barrera" o sea a base de lienzos desmontables, de madera que se iban encajando a medida.

El que aparezca un hombre de confianza del rey y de alta graduación en los preparativos, nos anuncia la mano regia en la acción. Por tanto iniciativa ducal, pero con aprobación de los Reyes.

\section{C.4. ¿Porqué apoyaron los Reyes la iniciativa ducal?}

La marcha de Boabdil de Granada en 1492, con la consiguiente preparación de una flota y diversos viajes de reconocimiento efectuados por orden del Secretario Real Hernando de Zafra, había proporcionado un abundante material escrito sobre el estado de descomposición en el norte del Sultanato de Fez y Orán ${ }^{24}$.

Hernando de Zafra cref́a posible una actuación rápida en esta zona en beneficio de España, pero los Reyes Católicos nunca llegaron a decidirse. Cuando Medina Sidonia plantea la posibilidad de ocupar Melilla, debieron pensar en apoyarlo por varias razones:

-En primer lugar el riesgo corría de parte del Duque. Económicamente, en los preparativos, toda la base y gasto de la expedición eran cargos del Medina Sidonia y sólo si la empresa triunfaba, la Monarquía cargaría con parte de éstas. Pensemos desde luego en las altas rentas del primero.

(24) CASTRIES, Henry, op. cit. Introducción.

FERNANDEZ DE CASTRO Y PEDRERA, Rafael, "Los primeros exploradores de la Costa de: Melilla", Africa, Revista de Tropas Coloniales, Madrid, $\mathrm{n}^{9} 19$ y 20, julio-agosto 1943, p.: 30-33. 
- Podía ser también una baza para negociar la devolución de Gibraltar en un momento dado 25 .

-Por último y más importante, el apoyo vino porque de una u otra manera los Reyes Católicos ya habían pensado ocupar, más tarde o más temprano Melilla. Si la acción no entraba en ese momento dentro de sus plancs, tampoco iba en contra de ellos, pues en caso negativo no se hubiera llevado a cabo.

Sea como fuere, con la gestión directa del Duque de Medina Sidonia a través de su contador Pedro de Estopiñán, y controlado y organizado en parte por los Reyes Católicos a través del Capitán General de Artillería Francisco Ramírez de Madrid, se lleva a cabo la ocupación de la abandonada y semidestruida ciudad de Melilla, el 17 de septiembre de 1497.

\section{La ocupación de Melilla y sus consecuencias más inmediatas}

A partir del 17 de septiembre de 1497, los anhelos, las esperanzas y lo futurible, se hacen presentes. Y la realidad comienza a marcar la acción.

Los Reyes Católicos estaban inmersos en las Guerras de Italia y lo seguirían estando. Por esas fechas cl mismo Ramírez de Madrid constrúa en el Rosellón español la increible fortaleza de Salses: Europa reclama la atención de España.

Don Enrique, calificado como "apático Duque tan inclinado por carácter a repentinos arranques como desidioso para perseverar en lo comenzado"26 se da cuenta entonces del peso del mantenimiento de la Plaza: los gastos eran enormcs, aun para su saneada hacienda.

Melilla necesitaba grandes caudales de maravedises para su completa recdificación y a pesar de que la ocupación por sorpresiva fue incruenta, pronto comicnza la reacción de Fez.

Los Reyes Católicos en cuanto comprobaron como la acción había tenido éxito, recondujeron la situación para un mayor control de la empresa.

Melilla se le iba a Medina Sidonia de las manos conforme entraba a ser una atalaya defensiva.

Las relaciones entre los Reyes y el Duque sobre el mantenimiento de Mclilla y cuales iban a ser las obligaciones de ambos con respecto a la ciudad aparecen fijadas en varios asientos que se pactaron entre ambos.

Conocemos al menos la existencia de tres, y en ellos se especificaba a la perfección todos los detalles sobre la guarda y el mantenimiento de la Plaza ${ }^{27}$.

(25) LADERO QUESADA, Migucl Angel, en "Los scrioríos medievales en el ámbito de Cádiz y Jerez de la Frontera", art. cit., ha scñalado que para recompensar al Duque por la pérdida de Gibraltar (1503) se le reconoció cl Juro o ayuda de 4.400 .000 maravedises para mantenimiento de Melilla (1504).

(26) PALENCIA, Alonso de, op. cit., Tomo IV, p.: 266.

(27) En estos años, finales del siglo XV y principios del XVI, datan los asientos de Alcalá de Henares de 13 abril 1498 y Scvilla, 14 junio 1500. 
Estos interesantes documentos nos permiten extraer varias consecuencias. En primer lugar, y tal como señaló Sancho de Sopranis ${ }^{28}$ la villa tenía un carácter mixto: señorío regio y ducal.

Melilla aun a pesar de ser una ocupación del Medina Sidonia no era plaza de señorío ducal sino de realengo donde el duque era un Teniente de la misma con carácter de virrey.

Como Jesús Salafranca ha señalado ${ }^{29}$ la guarnición corría de parte del Medina Sidonia (421 soldados) y recibía para su aprovisionamiento 4.082 fanegas de trigo anuales sobre el pan de las tercias reales del arzobispado hispalense y gaditano.

También costeaba el Duque el flete de las fustas, gastos extraordinarios, acarreo del pan, averías, etc.

La libranza real era de 2.949 .789 maravedises más 1.000 .000 extraordinario para obras. Pero los Reyes ponían en Melilla guamición real, compuesta por 279 soldados. Si analizamos este contingente veremos como la monarquía se reservaba el envío de la totalidad de escuderos (200) (de a pie y a caballo) y la mayoría de espingarderos y tiradores (79).

Las fucrzas del Medina Sidonia eran sobre todo ballesteros (300).

¿Una ciudad que va a ser cabeza de puente para posteriores conquistas no necesita una potente caballería? Curiosamente la única caballería que habría en la villa era real.

Por otra parte, el mantenimicnto de Melilla era empresa costosísima. ¿De dónde salían los fondos para su guarda y tenencia?

Nicolás Cabrillana ${ }^{30}$ ha estudiado el modo como se encauzaba el torrente circulatorio hasta Málaga, que cobraría el Duque por privilegio concedido en Granada cl 27 de encro de 1501 cn virtud de una capitulación fechada en Sevilla un año antes: cl llamado Juro de Mclilla.

Según éste, los Reyes pagarían por la servidumbre del Duque 4.400 .000 maravedises y el Quinto real de la venta de esclavos. De todos modos sabemos que la empresa era deficitaria.

Los maravedises del Juro se sacaban de las rentas de lugares de realengo en buena parte de Andalucía.

Evidentemente los maravedises del Medina Sidonia se sacaban de sus rentas, procedentes de los lugares de señorío.

(28) SANCHO DE SOPRANIS, Hipólito, El Comendador Pedro de Estopiñán Conquistador de Melilla, Instituto de Estudios Africanos, Madrid, 1952, p.: 56

(29) SALAFRANCA ORTEGA, Jesús, Bosquejo histórico de la Población y Guarnición de Melilla 1497-1874, Granada, Excelentísimo Ayuntamiento de Melilla, 1987 p.: 13-21

(30) CABRILLANA, Nicolás, "Notas sobre las relaciones de Málaga con el Norte de Africa en el siglo XVI", Cuadernos de la Biblioteca Española de Tetuán. p.: 217 


\section{D.1. Función de Melilla en 1497}

Lo que de todos modos estaba claro cs que por ahora Melilla no iba a ser cabeza de puente, y que se preparaba (los asientos lo demuestran) para soportar una política de atalaya a largo plazo, poco brillante y muy costosa, incluso para las cuantiosas rentas ducales.

Precisamente todo aquello que al duque podía parecerle negativo: no había señoríos, ni privilegios, ni marquesados, únicamente una fortaleza costosa, sin caballería apenas, condenada a defenderse de los ataques de los de Fez, y solo dueña del territorio de murallas adentro presta a servir a la política exterior de los Reycs Católicos cuando se la necesitara. $Y$ esa función la ha desempeñado hasta finales del siglo XIX.

Queremos destacar finalmente un hecho que pudiera parecer a primera vista contradictorio. El Rey Fernando, en carta de 4 de octubre de 1504, ofrece a Don Juan de Guzmán la villa de Cazaza y el reino de Fez con sus fortalczas y aldeas y tierra y términos, para que la tuviese por título de mayorazgo con derccho a cederla a sus hijos con el título de Marqués de Cazaza, siempre y cuando el Duque la conquistase. El hecho se materializa al año siguiente y Don Juan pasa a ser Marqués de Cazaza (villa cercana a Mclilla que permanecería bajo la esfera de la Casa Medina Sidonia hasta su pérdida en 1532).

No sólo destacamos este hecho porque ha sido prácticamente ignorado por casi toda la historiografía sino porque señala un cambio y diferencia con respecto a Melilla.

El control real es aquif mucho menor, y pudicra entenderse concatenado con cl impulso que se le da al tema africano (Mazalquivir, Peñón Vclez, Orán ...) con el Cardenal Cisncros.

Aquí sí parece haber un intcrés real por impulsar un frente amplio en Africa. Pero ahora los mayores intereses, su intervención directa irán para la actual costa Argelina (Orán, Argel ...). La costa mediterránca de Fez reviste dentro de este impulso un carácter más marginal (excepto Velez de la Gomcra).

¿Pretendía el Rey crear un segundo frente, secundario, en esta zona ofreciéndole al Medina Sidonia beneficios en futuras conquistas? ¿Era ćste un modo de mantencr varios frentes en la zona? Este intento fracasó pero de todos modos es interesante comprobar como se da más importancia a las conquistas en la zona de la actual Argelia y Túnez, y no a las del vecino Sultanato de Fez: El problema pirata y turco acababa de empezar. La actuación española durante todo cl siglo XVI vendrá determinada por estos factores: postura defensiva ante cl ataque continuo de turcos y piratas berberiscos.

Cazaza frente a Melilla, nos evidencia que la primera si fue una villa o fortaleza de señorío, pero a niveles prácticos ambas constituran plazas defensivas con poco intcrés productivo o económico. El Duque no iba a obtener ningún beneficio por clla 
y su intervención en la costa norteafricana se eclipsa, a pesar de ser Capitán General de la Costa, a partir de entonces ${ }^{31}$.

\section{D.2. Conclusiones}

No nos parece oportuno ocuparnos aquí del desarrollo posterior de Melilla en el siglo XVI: cambiante y rico panorama, que exigirfa otros trabajos.

Hemos intentado englobar la ocupación de Melilla en un complejo momento de la política española, momento donde se entremezclan diferentes componentes no solo interiores sino exteriores.

La actuación del Duque de Medina Sidonia aparece bien justificada por el papel que él mismó desempeñaba en la política española. Pero lo de Melilla explícita bien cual era su papel político y cuales cran las miras más globales de los Reyes Católicos.

La ocupación no pudo explicar por sí misma una política definida en Africa, al menos en 1497. Y si puede entenderse desde luego desde muchos puntos de vista y todos son válidos, hemos intentado hacerlo aquí como un reflejo más de las relaciones entre los Reyes Católicos con el Duque de Medina Sidonia.

\section{E. Estudio global de la bibliografia específica sobre la ocupación de Melilla}

Cuando nos planteamos la realización de este trabajo y acudimos a buscar y reunir una bibliografía específica sobre la ocupación de Melilla, además del alto número de trabajos, observamos una serie de pautas inherentes en ellos que por parecernos interesantes nos han movido a dedicar este último punto a un somero estudio que nos permita tener una visión global sobre csta bibliografía.

Si la mayor parte de las veces el investigador puede encontrar como una dificultad difícil de supcrar la incxistencia de estudios previos sobre un tema, no es este aparentemente nuestro caso.

La ocupación de Mclilla en 1497 ha despertado notablemente la atención de estudiosos c investigadores, lo que nos ha deparado una buena muestra de artículos y libros sobre cl particular (no menos de 60 trabajos) (Anexo).

Pcro este hecho, que pudicra parecer a primera vista positivo no es representativo de la realidad.

Un estudio pormenorizado de todos estos trabajos, ofrece otra imagen, distante de aquello que pudicra permitimos hacer una valoración positiva de la cuestión:

(31) Con posterioridad, la función de los Duques de Medina Sidonia será muy marginal con respecto a los temas africanos. Darío Cabanelas Rodríguez, en su artículo "El Duque de Medina Sidonia y las relaciones entre Marruecos y España en tiempos de Felipe II", Revista Miscelánea de Estudios árabes y hebraicos, año 1974, volumen XXIII, fascículo 10, p.: 7-27, analiza en parte algunas actuaciones secundarias de los Duques durante el siglo XVI. 
-Por un lado, tal profusión de artículos no ha abarcado un abanico temático para diversificar y ofrecer nuevas aportaciones sobre unos u otros aspectos concretos.

Por el contrario, la mayor parte de ellos son resúmenes de la cuestión, más o menos acertados, y no aportaciones nuevas.

De esta tónica rescataremos y destacaremos varios trabajos originales como los de Henry de Castries (1921), Tomás García Figueras (1947), Patricio Prieto Llovera (1951) e Hipolito Sancho de Sopranis (1952) que han aportado nuevas visiones o puntos de vista originales, o bien han intentado sustentar sus hipótesis con un mínimo de rigor.

-Por otra parte, las aportaciones documentales sc han venido haciendo sobrc las fuentes clásicas de Medina, Barrantes y Zurita y lo que se ve en ellos es un intento de interpretarlas de uno u otro modo, pero sin hacer en muchos casos un análisis crítico de éstas, casi todas ellas publicadas por cierto en la Colección de Documentos Inéditos para la historia de España.

En este punto vuelve a resaltar de nuevo la monumental obra de Henry de Castries (1921) que en su volumen I, ofrece una visión de la Melilla del siglo XVI tan original como insuperada hasta hoy desde nucstro punto de vista, pues Castrics acude directamente a las fuentes documentales del Archivo General de Simancas y de la Biblioteca del Escorial. Su línea ha sido seguida en fechas muy cercanas (y de un modo demasiado evidente) por la también francesa Monique Polo (1986).

En líneas generales, salvo excepciones, no hay por tanto un intento de análisis documental o de revisión bibliográfica sobre lo ya publicado.

-Y este es un tercer punto, pues observamos en casi todos ellos una ignorancia no ya sobre los estudios precedentes, sino sobre las aportaciones o esclarecimientos que algunos de ellos pudieron haber arrojado.

Es así como vemos crrores repetidos hasta la actualidad cuando csas cuestiones ya fueron dilucidadas con anterioridad.

No ha habido ningún intento de clasificar y codificar la bibliografía existente, tal vez con la intención en cada caso de cerrar el tema con cl último trabajo publicado, ignorando lo antcrior.

De aquí se desprende un problema básico: la metodología. Algunos autores adolecen de cualquier metodología a la hora de cstudiar cl tema, y sc limitan a redactar lo extraido de las fuentes que utilizan con suposiciones que llevan a la confusión, sin plantearlas como hipótesis (Rafacl Fernández de Castro). Otros no pretenden más que efectuar resúmenes o estados de la cucstión heredando todos los errores de lo ya publicado y casi todos incluyen esos errores aun en cl caso de querer efectuar aportaciones que quicren ser nuevas.

Volvemos a resaltar entre el corpus de investigadores al francés Henry de Castries, al historiador Hipólito Sancho de Sopranis y no tanto por su metodología como por su crudición a Tomás García Figueras.

Estos últimos son historiadores que aun habiendo dedicado algunos estudios a Mclilla, han centrado su producción historiográfica en temas más generales entre los 
que han destacado abicrtamente.

Sus aportaciones son metodológicamente más correctas que las de los historiadores, cronistas, o cstudiosos locales, con limitaciones más cvidentes.

Como para sacarles los colores a cualquiera puede ser el ¿artículo? firmado por A.B. (1942) sobre la ocupación de Melilla en las historias árabes y donde tras el pomposo título, el autor en cinco líneas se disculpa diciendo desconocer hasta ese momento cualquicr referencia en esas crónicas. El sabor a encargo es tan evidente como la falta de scriedad del editor de la revista.

Otros de los rasgos que asombran cuando se estudia esa bibliografía es lo prolifico de ciertos autores a la hora de publicar, pero más asombra cuando se comprueba como algunos artículos son editados con leves retoques en jseis o sicte publicaciones distintas!

Este es cl caso cvidente de Rafael Fernández de Castro, (cronista oficial de Melilla) que llego a publicar catorce artículos sobre una cuestión que hubiera despachado en tres, o de Tomás García Figueras (ocho publicaciones aunque mucho más divcrsificadas temáticamente).

También podemos analizar la cuestión idcológica de los autores citados pues en esto estribaría parte de su objctividad - subjetividad.

Digamos que Mclilla como Plaza de Soberanía en cl Norte del Protectorado siempre fuc punto de mira privilegiado de aquellos que pretendían justificar la presencia española en Africa. Así, utilizando la historia de Melilla podía remontarse a 1497 esta presencia y justificar acciones que a nivel intelectual cstaban englobadas dentro del Africanismo cspañol.

Es así como la historia de Melilla (sicmpre olvidada en los siglos XVI al XIX), cn cste caso su "gloriosa conquista" en 1497, sirvió o fue utilizada por cste movimiento africanista del siglo XX para una autojustificación que hoy puede parecernos más que dudosa.

No es extraño que Tomás García Figucras (insigne africanista que ejerció altos cargos de responsabilidad en cl Protectorado Español en Marruccos) o Rafacl Fernández de Castro formen la base de gran parte de este corpus, concretamente cl $35 \%$ de todo lo publicado.

Se observa perfectamente esta tendencia: (Gráfico) en los años donde aparecen publicados artículos; pues se agrupan cn varios períodos muy vinculados a la historia de Melilla y cl Protectorado:

-1890-1895: Campaña de Margallo 1893. Melilla (cinco trabajos).

-1920-1925: Campaña de 1921. Marruccos: Pacificación (cuatro trabajos).

-1930-1935: Nucvo impulso y rcoricntación del Protectorado durante la II República (ocho trabajos):

-1936-1940: Bache de la Guerra Civil.

-1940-1955: Postgucrra española y nueva cohesión del sentimiento africanista español (24 trabajos).

La Independencia de Marruecos en 1956 conlleva una larga etapa de inactividad 
"cditorial" hasta que a partir de 1970 comienza un nuevo auge, pero con otras connotaciones:

-1970-1985: Pequeños artículos-resumen, publicados en perídicos, (diez trabajos).

-1985: Nucvo auge con una diversidad tanto temática como de enfoque, y una mayor metodología en los estudios (seis trabajos).

Este análisis nos lleva al centro de la cuestión y a plantearnos que el principal defecto de casi todo lo publicado es el metodológico, tal vez impulsado por un planteamiento ideologico, donde se utiliza la historia (muchas veces inconscientemente) como intento de justificación gloriosa del presente.

Si el hecho puede parecernos hoy más que deplorable, nos ha legado un producción con unas taras evidentes.

Por último dentro de este breve repaso bibliográfico comentaremos el artículo que el famoso y extravagante dramaturgo Fernando Arrabal ha dedicado al tema.

Arrabal, melillense furibundo, además de pedir para Melilla la capitalidad de España, publicó un curioso artículo en el diario El País (1987) "Melilla y los Testículos del Dragón" que aporta un rasgo tan colorista como surrealista a la citada ocupación. Basado tanto en sus propios recucrdos de la ciudad como en el artículo de Monique Polo (1986) (que Arrabal utiliza descaradamente) no cabe duda que es al menos una de las aportaciones más originales sobre cl tema. 


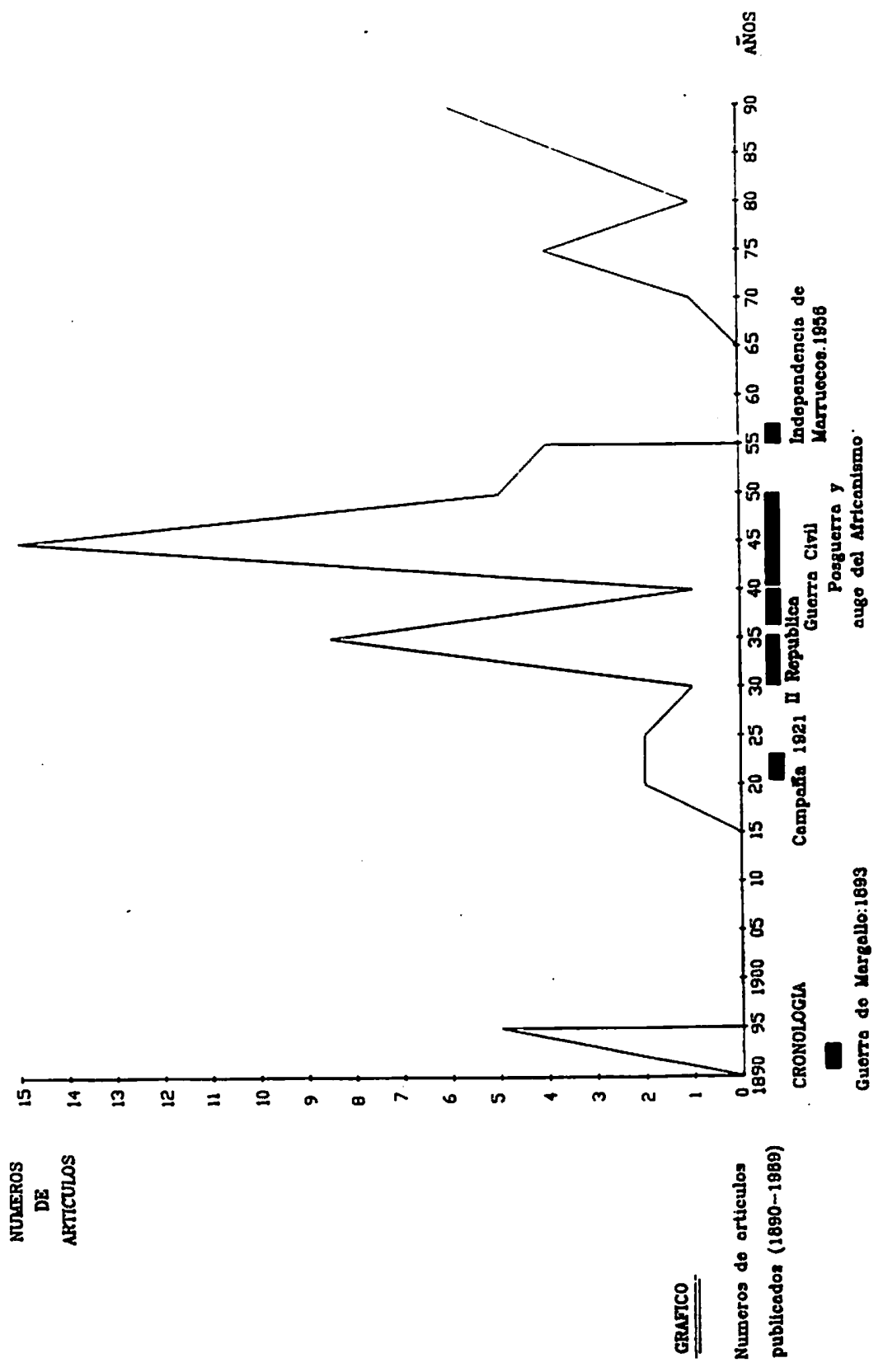




\section{Fuentes}

AFRICANO, Juan Lcón. Al-Hasan - Ben Muh, Al-Wazzan Al-Fasi: Descripción de Africa y de las cosas notables que en ella se encuentran. Sección $6^{\mathrm{a}} \mathrm{n}^{2} 5$. Reeditada en Imprenta Imperio, 1952. Publicaciones del Instituto General Franco de estudios e investigación hispano-árabe.

BARRANTES MALDONADO, Pedro: Ilustraciones de la Casa de Niebla 154. En memorial histórico español publicado por la Real Academia española de la Historia, bajo la dirección del Sr. D. Pascual de Gayangos. Tomo X y tomo II, capítulo IV, p. 404 y siguiente. Madrid, Imprenta Nacional, 1857.

BERNALDEZ, Andrés, Cronista de los Reyes Católicos, Cura de los Palacios: Crónica de Don Fernando y Doña Isabel. C.L.V.I. Publicada en el tomo III de Crónicas de los Reyes de Castilla. Colección Rivadeneyra, tomo LXX, p. 692.

ESTRADA, Juan Antonio de: Población General de España. Madrid, Imprenta Mercurio, 1748.

MEDINA, Pedro de, Cronista de los Duques de Medina Sidonia: Crónica de los muy excelentes señores Duques de Medina Sidonia1561. En CO.DO.IN. Tomo XXXIX. P.: 317-321.

ZURITA, Jerónimo: Anales. Historia del Rey Don Hernando el Católico, de las Empresas y ligas de Italia compuesta por Geronimo Zurita. Chronista del Reyno de Aragon. Tomo V. Con licencias y privilegios. Impreso en Çaragoça por los herederos de Pedro Lanajo y Lamorca, Impresores del Reyno de Aragón y de la Universidad, año 1580, libro III, cap. XVI, folio 106.

PADILLA, Lorenzo de: Cronista de Don Felipe I, llamado el Hermoso. En CO.DO.IN. Tomo VIII, p.: 1-267.

Relación de la conquista de las fortalezas de Melillay Cazaza por el Duque de Medina Sidonia, año 1496. Bibliotcca Nacional, númcro 2.345, folio 192-192 v. 193.

\section{Bibliografía (En orden cronológico)}

PIÑERO, Agustín: “Conquista de Mclilla por los Jcrczanos”. El Guadalete (Jcrcz) 9 octubre 1892.

PIÑERO, Agustín: "El Conquistador de Mclilla". El Guadalete (Jercz) 7 novicmbrc 1893.

LEON Y DOMINGUEZ, José María: "Curiosidades Gaditanas. Toma de Mclilla por el gaditano Pedro de Estopiñán". Diario de Cádiz, 16 noviembre 1893. Recogido en Recuerdos Gaditanos. Cádiz, 1897. p.: 50-61.

PIÑERO, Agustín: "Más sobre el Conquistador de Mclilla". El Guadalete, 28 novicmbre 1893.

IBARRA RODRIGUEZ, Eduardo: "La conquista de Melilla en 1497". La España Moderna. Madrid, LXI, 1894, p. 121-140. Publicado posteriormente en la Revista Mauritania, Tánger, año 16, ñ 188, 1 julio 1943. p. 197-200.

RODRIGUEZ RIVERO, Adollo: "Curiosidades melillenses. Datos para la Historia de Melilla y rclación de la misma con cl Comendador Don Pedro de Estopiñ̃ín". Ileraldo de Mclilla. Mclilla 6 y 8 noviembre 1915 , s. ps.

GARCIA FIGUERAS, Tomás: "La Conquista de Mclilla por Pedro de Estopiñán". Marruecos (Madrid) 1919. 
DE CASTRIES, Henry: Les Sources inédites de L'Ilistorie du Maroc, Archives et Bibliothéques d'Espagne. Tome I, Paris. Ed.: Ernest Leroux, 1921. p.: I-XXVIII.

FERNANDEZ DE CASTRO Y PEDRERA, Rafael: "Páginas históricas. La conquista de Melilla (17 de septiembre de 1497)". Africa, Revista de Tropas Coloniales. Ceuta, $\mathrm{n}^{2} 5$, mayo 1924. s.p.

FERNANDEZ DE CASTRO Y PEDRERA, Rafacl: "Los primeros días de la Melilla cspañola". Conferencia dada en el Atenco Científico, Literario y de Estudios Africanistas de Melilla. Melilla 1927.

FERNANDEZ DE CASTRO Y PEDRERA, Rafael: "Los primeros días de la Melilla Española". Colección de artículos publicados en el Telegrama del Rif (Melilla) septiembre de 1930.

GARCIA FIGUERAS, Tomás: "El Conquistador de Melilla". Africa, Revista de Tropas Coloniales. Encro 1931.

FERNANDEZ DE CASTRO Y PEDRERA, Rafacl: "Mclilla y sus fortificaciones en la primera mitad del siglo XVI". Africa, Revista de Tropas Coloniales, Ccuta, $\mathrm{n}^{0} 76$, abril 1931, p. $76-$ 78.

FERNANDEZ DE CASTRO Y PEDRERA, Rafael: "Mclilla y sus Capitulacioncs con los Reyes Católicos". Africa, Revista de Tropas Coloniales, Ceuta, $n^{2} 81$, scpticmbre 1931, p. 171-173.

GARCIA FIGUERAS, Vicente: "El jerezano Pcdro de Estopinán y Virués, conquistador de Melilla y Adelantado de Indias", Cádiz, 1933. Discurso en su recepción pública en la Real Academia Hispanoamericana de Cádiz, s.p.

GARCIA FIGUERAS, Vicente: "La Conquista de Melilla (1497)". Africa, Revista de Tropas Coloniales, enero 1933.

GARCIA FIGUERAS, Tomás: "El Conquistador de Melilla. Datos para la biografía de Pedro de Estopiñán". Africa, Revista de Tropas Coloniales, enero 1934.

FERNANDO DE CASTRO Y PEDRERA, Rafael: "Hojas del siglo XV. Los primeros Capitancs y Alcaides de la Mclilla española", Africa, Revista de Tropas Coloniales, Ceuta, $\mathrm{n}^{2} 115$, julio 1934, p. 136-137.

FERNANDEZ DE CASTRO Y PEDRERA, Rafael: "Melilla en el siglo XV. Los primeros Capitanes y Alcaides de la Melilla española" Mauritania, Tánger, año 12, n 140, 1 julio 1939. p. 213-215.

S.A.: "Jercz y Melilla", Mauritania, Tánger, $\mathrm{n}^{\circledR}$ 175, año 15, 1 junio 1942, p. 193.

FERNANDEZ DE CASTRO Y PEDRERA, Rafael: "17 de septiembre de 1497. Anteceden-

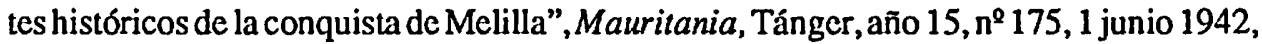
p. 211-213.

RODRIGUEZ DEL RIVERO, Adolfo: "Datos varios sobre Pedro de Estopinán y la conquista de Melilla". Mauritania, Tánger, Año 15, $\mathrm{n}^{\circledR} 175,1$ junio 1942, p. 214-215.

GARCIA FIGUERAS, Tomás: "El conquistador de Melilla, datos para la biografía de Pedro de Estopiñán". Mauritania, Tánger, año 15, n² 175, 1 junio 1942, p. 216-217 (Firma $\mathrm{XXX)}$.

SANCHO DE SOPRANIS, Hipólito: "Los familiares inmediatos del Conquistador de Melilla, Pedro de Estopiñán". Mauritania, Tánger,año 15, n² 175, 1 junio 1942: p. 218-223.

SANCHO DE SOPRANIS, Hipólito: "El abolengo marroquí de la familia Estopiñán, Juan Manuel de Estopiñán en Larache, 1689". Mauritania, Tánger, año 15, n² 175, 1 junio 1942, 


\section{p. 224-225.}

MELGAR, ¿Francisco?: “El Duque de Medina Sidonia y la conquista de Melilla”. Mauritania, Tánger, año $15, \mathrm{n}^{2} 175,1$ junio 1942, p. 226-228.

GARCIA FIGUERAS, Tomás: "Dificultades de España con Portugal con motivo de la ocupación de Melilla”. Mauritania, Tánger, año 15, $\mathrm{n}^{2} 175,1$ junio 1942, p.: 229.

A.B.: "La ocupación de Melilla en las historias árabes". Mauritania, Tánger, año 15, n²175, 1 junio 1942, p.: 230.

SANCHO DE SOPRANIS, Hipólito: "Cronología de Pedro de Estopiñán". Mauritania, Tánger, año 15, $\mathrm{n}^{9} 175,1$ junio 1942, p.: 213. (Aparece sin firmar).

GARCIA FIGUERAS, Tomás(V. de M.): "Bibliografía de la ocupación de Melilla".Mauritania, Tánger, año 15, $\mathrm{n}^{2} 175,1$ junio 1942, p.: 232.

FERNANDEZ DE CASTRO Y PEDRERA, Rafael: "Colón frente a la ocupación de Mclilla. El Almirante se oponía a la empresa africana". El Español, Madrid, n² 55, 1943. p. 13 y 16.

FERNANDEZ DE CASTRO Y PEDRERA, Rafacl: "Los primeros exploradores de la costa de Melilla". Africa, Revista de Tropas Coloniales, Madrid, $\mathrm{n}^{9} 19$ y 20 (extr.), julio-agosto 1943, p. 30-33.

FERNANDEZ DE CASTRO Y PEDRERA, Rafael: Melilla Prehispánica. Instituto de Estudios Políticos. Madrid, 1945.

Documentos relacionados con el Conquistador de Melilla, Pedro de Estopiñán. Separata de "Archivo Hispalense", segunda época, número 16, Sevilla, 1946.

GARCIA FIGUERAS, Tomás: "La ocupación de Melilla en el Pensamiento Político de los Reyes Católicos". Conmemoración del 450 Aniversario de la Conquista de Melilla. Curso de Conferencias. Melilla 15, 16 y 17 septiembre 1947. p. 13-36. Publicado también en: Miscelánea de Estudios Históricos sobre Marruecos. Larache, Editora Marroquí, 1949, p. 9-47.

SANCHO MAYI, Hipólito: "La Casa de Medina Sidonia y su participación en la Conquista, la figura del conquisador el Jerezano Pedro de Estopiñán según las últimas investigaciones". Conmemoración del 450 Aniversario de la Conquista de Melilla. Curso de Conferencias. Melilla 15, 16 y 17 septiembre 1947 p. 41-72.

FERNANDEZ DE CASTRO Y PEDRERA, Rafael: "La Conquista de Melilla, sus preparativos, la ocupación, capitulaciones de los Reyes Católicos con cl Duque de Medina Sidonia, los primeros días de la Melilla Española". Conmemoración del 450 Aniversario de la Conquista de Melilla. Curso de Conferencias. Melilla 15, 16 y 17 septiembre 1947, pp.: 77-96.

FERNANDEZ DE CASTRO Y PEDRERA, Rafael: "La Conquista de Melilla bajo el reinado de los Reyes Católicos". Curso de Conferencias sobre la Política Africana de los Reyes Católicos. Valladolid, 1951, tomo 3,p. 111-113.

PRIETO Y LLOVERA, Patricio: "La Conquista de Melilla y el tercer viaje de Colón". Africa, número 118,1951, p. 484-488.

FERNANDEZ DE CASTRO Y PEDRERA, Rafael: "Los primeros exploradores españoles del Africa Mediterránea en el siglo XV". Selección de Conferencias pronunciadas en la Academia de Interventores durante el curso 1950-51. Tetuán, Imprenta Cremades, 1951, p. 49-61.

SANCHO DE SOPRANIS, Hipólito: El comendador Pedro de Estopiñán, conquistador de Melilla, Madrid, 1952 (1953). Instituto de Estudios Africanos. 
MALDONADO VAZQUEZ, Eduardo: "Melilla y Sidi Uariach". Africa, enero 1968.

DOMINGUEZ SANCHEZ, Constantino: "Aniversario de la Conquista de Melilla por Pedro de Estopiñán". Telegrama Melilla, 13 octubre 1974.

DOMINGUEZ SANCHEZ, Constantino: "MelillaEspañola(1497-1556)" Telegrama Melilla, 18 octubre 1974.

SANS PUIG, José M", "Pedro de Estopiñán, conquistador de Melilla", Historia y Vida, Barcelona-Madrid, $n^{\circ} 98$, mayo 1976, pp. 8 y 10.

DOMINGUEZ SANCHEZ, Constantino: "Y habiendo grandes diferencias en Africa" Telegrama Melilla, 16 septiembre 1976.

MIR BERLANGA, Francisco: "La Conquista de Melilla según la crónica de Pedro de Mcdina y la descripción de Africa de Hassan Ben Moh el Wazzan, conocido por Juan León Africano", En Melilla en los pasados siglos y otras historias. Madrid, 1980, p. 35-41.

MIR BERLANGA, Francisco: "Una nueva versión de la Conquista de Melilla". Telegrama Melilla, 18 septiembre 1981.

MIR BERLANGA, Francisco: "Don Pedro de Estopiñán”.Prensa 3. Melilla, número 10, 1983.

MIR BERLANGA, Francisco: "El primer presupuesto de Melilla". En Melilla, Floresta de Pequeñas Historias. Granada. 1983, p.: 49.

TORRES GARCIA, Francisco: "La Conquista de Melilla bajo el reinado de los Reyes Católicos". Revista de Historia Militar, año XXX, número 61, 1986. p. 161-178.

POLO, Monique: "La vida cotidiana en Melilla en el siglo XVI" Criticón, (Toulouse) 36, 1986, p. 5-31.

CALDERONRUIZ, Lucasy PONCEGOMEZ, Adela: "Sidi Guariach, SantoPatron Musulmán". Melilla hoy, 3 mayo 1987.

ARRABAL, Fernando: "Mclilla y los Testículos del Dragón". El País, 6 marzo, 1987.

GOZALBES CRAVIOTO, Enrique: "El Epilogo de la Melilla Musulmana" España y el Norte de Africa. Bases Históricas de una relación Fundamental. Granada. Universidad 1987.

SALAFRANCA ORTEGA, Jcsús: Bosquejo Histórico de la Población y Guarnición de Melilla 1497-1874. Melilla. Ayuntamiento 1987. 